\title{
Estimation of flavoniods, antimicrobial, antitumor and anticancer activity of Carissa opaca fruits
}

\author{
Sumaira Sahreen ${ }^{1,2^{*}}$, Muhammad Rashid Khan ${ }^{2}$, Rahmat Ali Khan ${ }^{2,3^{*}}$ and Naseer Ali Shah ${ }^{2}$
}

\begin{abstract}
Background: Carissa opaca Stapf ex Hanes fruits is traditionally used in the treatment of asthma, hepatitis and microbial infections. The present study was arranged to investigate the antimicrobial, cytotoxic and antitumor activity of various fractions of $C$. opaca extract and its bioactive metabolites responsible for that activity.

Methods: To characterize various fractions of C.opaca antibacterial, antifungal, cytotoxic and antitumor assays are used. Eight strains of bacteria including Bacillus subtilis, Enterobactor aerogenes, Escherichia coli, Klebsiella pneumoniae, Micrococcus luteus, Pseudomonas aeroginosa, Salmonella typhy, and Staphylococcus aureus and four strains of fungal viz: Aspergillus flavus, Aspergillus fumigatus, Aspergillus niger and Fusarium solani are used. Brine shrimps and potato dics are used for anticancer and antitumor potency of extract. High performance liquid chromatography (HPLC) is utilized for determination of bioactive metabolites responsible for the activity.

Results: HPLC chromatogram revealed the presence of orientin, isoquercetin, myricetin and apigenin. Various fractions of C. oapca showed significant antibacterial, antitumor and anticancer activity. In case of C. opaca fruit inhibition growth of Aspergillus niger was ranged between $23.2 \pm 1.36 \%$ to $43.3 \pm 2.39 \%$, Aspergillus flavus ranged between $27.6 \pm 1.39 \%$ to $65.6 \pm 3.44 \%$, Aspergillus fumigatus ranged between $13.2 \pm 1.00 \%$ to $52.4 \pm 1.54 \%$ and Fusarium solani ranged between $10.5 \pm 1.02 \%$ to $14.6 \pm 1.74 \%$.
\end{abstract}

Conclusion: It can be concluded that, various fractions of C.opaca are accessible source of ethno pharmacy as they are consumed in different areas of Pakistan with ultimate health compensations.

Keywords: Carissa opaca, High performance liquid chromatography, Escherichia coli, Anticancer

\section{Background}

Carissa opaca Stapf ex Hanes is widely distributed from Punjab-Himalayas up to $6000 \mathrm{ft}$, in Murree (Pakistan) as well as in some areas of India, Burma and Sri Lanka [1] traditionally used in the treatment of asthma [2], cardiac dysfunction [3], microbial infection [4], cough, diarrhea and fever [5]. In spite of its popular uses, there is no information about secondary metabolites. The scientific testimonials about discovery of plants as reservoirs of bioactive substances for the deterrence of degenerative and chronic ailments are in frequent progress. Indeed, the origin of various remedial therapies is due to plant secondary metabolites. Plants that possess

\footnotetext{
*Correspondence: sumaira@yahoo.com; Rahmatgul_81@yahoo.com ${ }^{1}$ Botanical Sciences Division, Pakistan Museum of Natural History, Garden Avenue, Shakarparian, Islamabad, Pakistan

${ }^{3}$ Department of Biotechnology, Faculty of Biological Sciences, University of Science and Technology, 28100 Bannu, KPK, Pakistan

Full list of author information is available at the end of the article
}

flavonoids have strong anti-inflammatory, antiviral, antioxidant, antiallergenic, anti-fungal, antibacterial, anticancer, cytotoxic and hepatoprotective activities thus, generated curiosity about flavonoid containing plants $[6,7]$. In the recent years, medicinal plants are supplementary focused regarding to therapeutic properties of traditional medicines in the treatment of various incoming diseases. It has become necessary to find out new antimicrobial drugs having diverse chemical structures so that they can deactivate new lethal microorganisms $[8,9]$. Hence, an outstanding chemical diversity found in botanicals may be of great potential to relate with new antimicrobial agents. These antimicrobial agents are functional against plant and human pathogens. Previous literature reports that the bioassay-guided fractionation and antimicrobial activity of plant extracts yield active principles [10]. Antimicrobial agents of botanicals with massive remedial potential to heal many infectious 
diseases are void of side effects in comparison to synthetic drugs. Medicinal plants offer a considerable novel antimicrobial therapeutic potential and adjunct treatment against resistant microbial strains. Hence, it has become crucial to explore new antimicrobial agents from natural resources. Although the ethnobotanical literature about $C$. opaca is well acknowledged, yet very little scientific information about its activity against microorganism is available. Cancer, being a world-wide health problem, is treated with clinical therapies including chemotherapy, surgery, radiation therapy and so on by using synthetic medicines [11]. Toxic side effects of synthetic medicines have made a comeback for herbal medicine to improve our present and future health needs. Thus, development of simple suitable and economical assay systems for prescreening of a wide range of samples can seek advantageous as alternatives to prolonged animal trials for the discovery of new anticancer drugs. Various bioassay methods have been assessed for the antitumor or anticancer activity of plant extract/fractions or compounds. Several famous and noteworthy discoveries like vincristine, vinblastine the podophyllotoxin derivatives and 10-hydroxy-campothecin are the outcome of these methods and also derived from botanicals. Sharma [11] reported that diterpene resins of Croton species have been possibly prove to be useful in cancer therapy. It is reported that, there is a strong correlation between human nasopharyngeal carcinoma and brine shrimp toxicity. Brine shrimp lethality assay (BSLA) provide a front-line screen to back up more specific and expensive bioassays for isolation of active compounds due to inexpensive and rapid means of standardization of bioactivity in heterogeneous botanical products [12]. Brine shrimp lethality test is going to be practiced routinely as an indicator of possible cytotoxic properties in order to reveal new anticancer drugs. Cytotoxic assays are being frequently applied for the analysis of mycotoxins, anesthetics, dinoflagelate toxins and marine toxicants. Thus, using these cytotoxic assays, many novel pesticidal and anticancer natural products have been documented [13,14]. Antitumor potato disc assay using Agrobacterium tumefaciens is considered as quick, lowpriced and consistent prescreening for antitumor agents of botanicals [15]. It is anticipated that this study would lead to formulation of new and more potent antimicrobial and anticancer drugs of natural origin.

\section{Methods}

\section{Plant collection}

Fruits of C. opaca were obtained in March-April 2011 from Abbottabad of Northern Pakistan, recognized by their local names and validated by Dr. Mir Ajab Khan, Department of Plant Sciences, Quaid-i-Azam University, Islamabad, Pakistan. A voucher specimen with Accession No. 24561 (C. opaca) was deposited at the Herbarium of Pakistan.

\section{Plant extraction}

The collected plant samples were cleaned to get rid of dust particles and then dried under shade for one to two weeks and made into fine powder. $2 \mathrm{~kg}$ of sample was extracted twice with $5 \mathrm{~L}$ of $95 \%$ methanol at $25^{\circ} \mathrm{C}$ for $48 \mathrm{~h}$. For filtration Whatman No. 1 filter paper was used and then filtrate was concentrated on rotary evaporator (Panchun Scientific Co., Kaohsiung, Taiwan) under reduced pressure at $40^{\circ} \mathrm{C}$. In order to resolve the compounds with escalating polarity, a part of the extract was suspended in distilled water and subjected to liquid-liquid partition by using solvents in a sequence of n-hexane, ethyl acetate, chloroform, butanol and water to obtain their soluble fractions. After fractioning, the solvent of respective fractions was also evaporated by rotary evaporator Extract was dried and then stored at $4^{\circ} \mathrm{C}$ for further in vitro investigation.

\section{High performance liquid chromatogrhy (HPLC) of methanolic fraction Sample preparation}

$50 \mathrm{mg}$ of C. opaca powder was extracted with $6 \mathrm{ml}$ of $25 \%$ hydrochloric acid and $20 \mathrm{ml}$ methanol for $1 \mathrm{hr}$. The obtained extract was filtered to a volumetric flask. The residue was heated twice with $20 \mathrm{ml}$ of methanol for $20 \mathrm{~min}$ to obtain the extract. The combined extract was diluted with methanol to $100 \mathrm{ml} .5 \mathrm{ml}$ portion of the solution was filtered and then was transferred to a volumetric flask and diluted with $10 \mathrm{ml}$ of methanol. The sample $(10 \mu \mathrm{l})$ was injected into the HPLC apparatus.

\section{HPLC determination}

Samples were analyzed on Agilent HPLC system. Separation was carried out through column 20RBAX ECLIPSE, XDB-C18, $(5 \mu \mathrm{m} ; 4.6 \times 150 \mathrm{~mm}$, Agilent USA) with UVVIS Spectra-Focus detector, injector-auto sampler. Solvent A $(0.05 \%$ trifluoroacetic acid) and solvent B (0.038\% trifluoroacetic acid in $83 \%$ acetonitrile $(\mathrm{v} / \mathrm{v})$ with the following gradient: $0-5 \mathrm{~min}, 15 \% \mathrm{~B}$ in A, $5-10 \mathrm{~min}, 70 \% \mathrm{~B}$ in A, 10$15 \mathrm{~min}, 70 \% \mathrm{~B}$ in A are used for separation The flow rate was $1 \mathrm{ml} / \mathrm{min}$ and injection volume was $10 \mu \mathrm{l}$. Eleven standard compounds including rutin, myricetin, vitexin, orientin, hyperoside, isovitexin, isoquercetin, luteolin, apigenin, kaempherol, and luteolin-7-glucoside were run for comparative detection and optimized. The calibration curves were defined for each compound in the range of sample quantity $0.02-0.5 \mu \mathrm{g}$. All samples were assayed in triplicate.

\section{Antibacterial assay}

The antibacterial potency of various fractions of C. opaca fruits was carried out through protocol of (Bagamboula et al. [16] using eight strains of bacteria were used; which were Bacillus subtilis (ATCC 6633), Enterobactor aerogenes (ATCC 13048), Escherichia coli (ATCC 15224), 
Table 1 Linear regression analysis of eleven standard flavonoids

\begin{tabular}{llllll}
\hline Compound & Retention time & Regression analysis & R & Linear range (ppm) & LOD (ppm) \\
\hline Rutin & 8.7 & $y=12571.3 x-16.62$ & 0.9873 & $10-250$ & 3 \\
Myricetin & 18.5 & $y=9643.4 x-11.07$ & 0.9919 & $10-200$ & 3.5 \\
Vitexin & 2.5 & $y=23085.1 x+3.72$ & 0.9932 & $10-100$ & 1 \\
Orientin & 2.75 & $y=36421.0 x+2.88$ & 0.9869 & $25-500$ & 3.2 \\
Hyperoside & 12.5 & $y=22758.9 x+1.56$ & 0.9865 & $10-250$ & 2.3 \\
Isovitexin & 3.7 & $y=31604.2 x+0.98$ & 0.9741 & $5-150$ & 1.8 \\
Luteolin & 2.01 & $y=19348.6 x+2.08$ & 0.9532 & $5-100$ & 2.1 \\
Isoquercetin & 6 & $y=26785.6 x+1.60$ & 0.9616 & $5-500$ & 2.5 \\
Apigenin & 4.7 & $y=10623.5 x-9.82$ & 0.9765 & $25-250$ & 1.2 \\
Kaempherol & 3.4 & $y=26182.8 x-+2.33$ & 0.9417 & $10-500$ & 1.34 \\
Luteolin-7-glucoside & 1.6 & $y=11434.6 x-10.72$ & 0.9536 & $5-100$ & 0.68 \\
\hline
\end{tabular}

Mean \pm SE $(n=3)$.

Klebsiella pneumoniae (MTCC 618), Micrococcus luteus (ATCC 10240), Pseudomonas aeroginosa (ATCC 27853), Salmonella typhy (ATCC 0650), and Staphylococcus aureus (ATCC 6538). Antibacterial activities were calculated as a mean of 3 replicates. Diameter of the clear zones, showing no bacterial growth, around each well was measured with the help of vernier caliper. Triplicate plates were prepared for each sample.

\section{Antifungal assay}

The agar tube dilution method was used for antifungal activity of plant extracts was determined according to the protocol reported by Duraipandiyan and Ignacimuthu [17] using Aspergillus flavus (0064), Aspergillus fumigatus (66), Aspergillus niger (0198) and Fusarium solani (0300).
Tubes were prepared in triplicate for each fungus species. Percentage inhibition of fungal growth for each concentration of fractions was determined by the following formula;

Percentage inhibition of fungal growth; $=(100$-linear growth in test $(\mathrm{mm}) /$ linear growth in control $(\mathrm{mm}) \times 100$

\section{Cytotoxic brine shrimp assay}

Various fractions of C.opaca were characterized according to Meyer-Alber et al. [18] using brine shrimps hatched in saline. 10-1000 PPM was incubated with brine shrimps. After $24 \mathrm{~h}$ of incubation survivors were

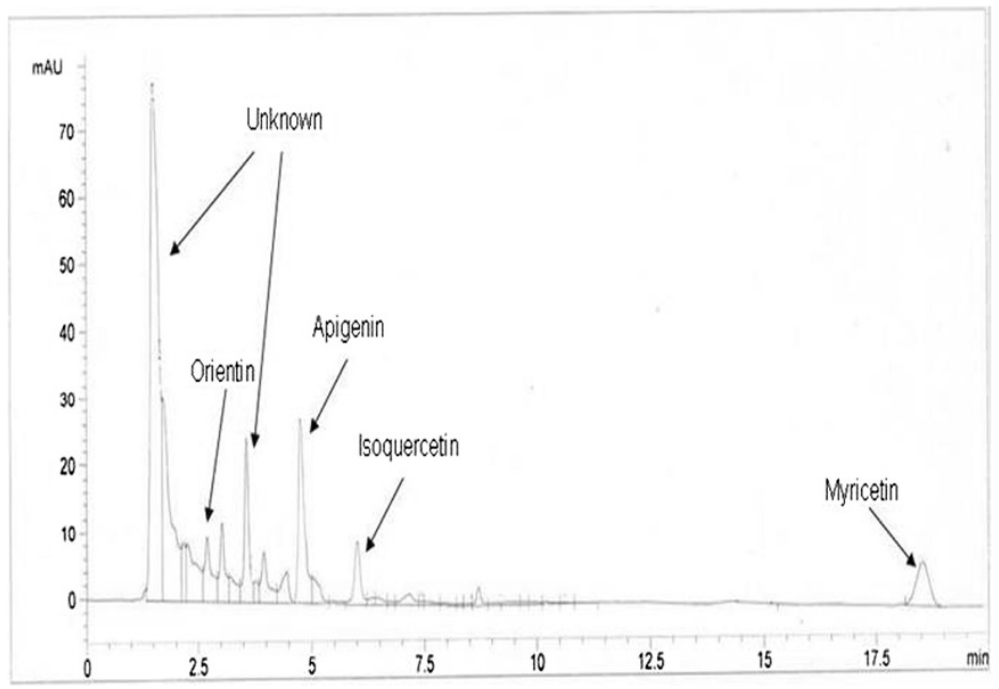

Figure 1 HPLC flavonoid profile of methanolic fraction of $\boldsymbol{C}$. opaca fruits. Conditions: mobile phase, $\mathrm{ACN}-\mathrm{dH}_{2} \mathrm{O} ;$ flow rate, $1 \mathrm{ml} \mathrm{min}{ }^{-1}$; detection wave length, $220 \mathrm{~nm}$; column temperature, $36^{\circ} \mathrm{C}$; injection volume, $10 \mu \mathrm{l}$. 
Table 2 HPLC flavonoids profile of methanolic fraction of C. opaca fruits

\begin{tabular}{lll}
\hline Compound & Retention time & Concentration $\boldsymbol{\mu g} / \mathbf{m g}$ of dry weight \\
\hline Orientin & 2.75 & 0.387 \\
Isoquercetin & 6 & 0.118 \\
Myricetin & 18.5 & 0.069 \\
Apigenin & 4.7 & 0.188 \\
\hline
\end{tabular}

Mean \pm SE ( $n=3)$.

counted with help of 3x magnifying glass and calculation was done using Abbots formula;

$\%$ Death $=($ Sample-control $/$ control $) \times 100$

$\mathrm{LD}_{50}$ was determined through prism graph pad software.

\section{Antitumor potato disc assay}

The potato disc method was used for anti-tumor activity of plant extracts as reported by Ferrigini et al. [19]. Number of tumors per disc was counted and percentage inhibition for each concentration was determined as follows:

\%age inhibition $=100-[($ average number of tumors of sample $) /$

(Average number of tumors of-ve control) $] \times 100$

$\mathrm{IC}_{50}$ was recorded using graph prism pad software.

\section{Statistical analysis}

Data of in vitro assays recorded were analyzed with help computerized Graph prism pad software to determined $\mathrm{EC}_{50}, \mathrm{IC}_{50}$ and $\mathrm{LD}_{50}$.

\section{Results}

\section{High performance liquid chromatography (HPLC) of} methanolic fractions of C.opaca

In the present study, HPLC-UV was preferred for the qualitative as well as quantitative analysis of methanolic fraction of C. opaca fruit. First of all, the experimental conditions were optimized to get the chromatograms with better resolution within a short resolution time and maximum UV absorption of sample. Hence, flavonoid standard compounds and the plant samples were quantified by assimilation of peak areas at $220 \mathrm{~nm}$ within runtime of 20 minutes. The standard solutions were injected in duplicate and the curves were constructed with the averages showing good linear correlation coefficient in the concentration range. All the standard flavonoids confirmed good linearity in a bit large concentration range. The conditions used directed towards the good separation of peaks that may be identified in the chromatogram as apigenin $\left(R_{t}=4.7\right)$, myricetin $\left(R_{t}=18.5\right)$, vitexin $\left(R_{t}=2.5\right)$, orientin $\left(R_{t}=2.75\right)$, hyperoside $\left(R_{t}=12.5\right)$, isovitexin $\left(R_{t}=3.7\right)$, isoquercetin $\left(R_{t}=6\right)$, rutin $\left(R_{t}=8.7\right)$, luteolin $\left(R_{t}=2.01\right)$, kaempherol $\left(R_{t}=3.4\right)$, luteolin-7-glucoside $\left(R_{t}=1.6\right)$ (Table 1$)$. A sample of $10 \mu \mathrm{l}$ of solution was injected to the instrument. Identification was done by comparing the obtained peaks of chromatogram of samples with the peaks of standard flavonoids in respect to retention time and UV-spectra. The chromatogram determining flavonoids components of methanolic fraction of C. opaca fruit in Figure 1. Table 2 summarized the flavonoids found in the methanolic fraction of $C$. opaca fruits as well as their retention time. Data indicated that methanolic fraction showed the presence of orientin, isoquercetin, myricetin and apigenin. There were some peaks having different retention time could not be identified; however, based on their chromatographic behaviors and UV spectra, they may correspond to unknown flavonoids compounds as presented in respective chromatogram.

\section{Antibacterial screening (MIC)}

The in vitro antibacterial activity of various fractions of C. opaca was evaluated by minimum inhibitory concentration (MIC) values. The MIC is the lowest concentration of test sample to inhibit visible growth of bacteria. The antibacterial activity was tested against both gram-negative bacteria as well as gram-positive bacteria. Table 3 describes the antibacterial activity as MIC value of various fractions of plant samples against tested bacteria. The results obtained from the present study for all tested bacteria ranged from 0.1 to $10 \mathrm{mg} / \mathrm{ml}$. Gram-positive bacteria such as Staphylococcus aureus was inhibited by MIC value $(1 \mathrm{mg} / \mathrm{ml})$ of HFC, MFC, $2.5 \mathrm{mg} / \mathrm{ml}$ of CFC, $5 \mathrm{mg} / \mathrm{ml}$ of BFC, while rest of the fractions didn't inhibit the growth of Staphylococcus aureus. On the other hand, Bacillus subtilis was inhibited

Table 3 Antibacterial screening as MIC $(\mathrm{mg} / \mathrm{ml})$ of various fractions of $C$. opaca against pathogenic bacterial strains

\begin{tabular}{|c|c|c|c|c|c|c|c|c|}
\hline Extracts & B. subtilis & E. aerogenes & E. coli & K. pneumoniae & M. luteus & S. typhy & P. aeroginosa & S. aureus \\
\hline MFC & 1 & 5 & - & 1 & - & 0.1 & 10 & 1 \\
\hline HFC & 0.1 & 1 & - & 0.1 & - & 0.1 & 1 & 1 \\
\hline EFC & 1.2 & 1 & - & 1 & - & 0.1 & 0.1 & - \\
\hline CFC & 1 & 0.1 & - & 1 & - & 0.5 & 10 & 2.5 \\
\hline BFC & - & 1 & - & 0.1 & - & 0.1 & 0.1 & 5 \\
\hline AFC & 2.5 & 1 & - & 1 & - & 0.5 & 10 & 10 \\
\hline
\end{tabular}

Mean \pm SE $(n=3)$. 
by HFC, (0.1 mg/ml); CFC, MFC (1 mg/ml); EFC $(1.2 \mathrm{mg} / \mathrm{ml})$; AFC, $(2.5 \mathrm{mg} / \mathrm{ml})$ while remaining fractions did not inhibit the growth of the respective bacteria. In case of gram negative bacteria Klebsiella pneumoniae's growth was inhibited by EFC, CFC, MFC, AFC $(1 \mathrm{mg} / \mathrm{ml})$ while remaining fractions did not inhibit the growth of the respective bacteria. Pseudomonas aeroginosa was inhibited by HFC $(1 \mathrm{mg} / \mathrm{ml})$; CFC, MFC, AFC $(10 \mathrm{mg} / \mathrm{ml})$ and rest of the fractions inhibited the growth at $0.1 \mathrm{mg} / \mathrm{ml}$. Growth of Salmonella typhy was inhibited by CFC, AFC $(0.5 \mathrm{mg} / \mathrm{ml})$ while rest of the fractions inhibited the growth at $0.1 \mathrm{mg} / \mathrm{ml}$. However, HFC, EFC and BFC inhibited the growth of Enterobacter aerogenes with MIC $(1 \mathrm{mg} / \mathrm{ml})$; CFC $(0.1 \mathrm{mg} / \mathrm{ml})$; MFC (5 mg/ml) while remaining fractions did not show inhibition of the concerned bacteria. MIC against Micrococcus luteus and Escherichia coli had no value, showing no antibacterial activity of any of the fractions.

\section{Antifungal screening}

The in vitro antifungal activity of various fractions of C. opaca fruit was evaluated against four fungal strains as shown in Table 4. In case of C. opaca fruit inhibition in growth of $A$. niger was ranged between $23.2 \pm 1.36 \%$ to $43.3 \pm 2.39 \%$, A. flavus ranged between $27.6 \pm 1.39 \%$ to $65.6 \pm 3.44 \%$, A. fumigatus ranged between $13.2 \pm$ $1.00 \%$ to $52.4 \pm 1.54 \%$ and $F$. solani ranged between $10.5 \pm 1.02 \%$ to $14.6 \pm 1.74 \%$.

\section{Cytotoxic screening}

Cytotoxic screening using brine shrimps bioassays was carried out to provide important preliminary data to select plant extracts. Cytotoxic effect of various fractions of C. opaca fruit was evaluated against brine shrimps growth under controlled condition as presented in Table 5. Generally this assay indicated that the survival of brine shrimps was inversely proportional to the concentration of different fractions. $\mathrm{LD}_{50}$ was the lowest concentration of test sample at which $50 \%$ death of shrimps occurred. Data of present study indicated that the order of $\mathrm{LD}_{50}$ of various fractions of C. opaca fruits was CFC > MFC > $\mathrm{AFC}>\mathrm{BFC}>\mathrm{EFC}>\mathrm{HFC}$.

Table 4 Antifungal screening of various fractions of C. opaca fruit against pathogenic fungal strains

\begin{tabular}{lllll}
\hline Extracts & \multicolumn{4}{c}{ \% inhibition of various fungal species } \\
\cline { 2 - 5 } & A. niger & F. solani & A. flavus & A. fumigatus \\
\hline HFC & $23.2 \pm 1.36$ & $13.4 \pm 2.35$ & $34.7 \pm 2.50$ & $13.2 \pm 1.00$ \\
EFC & $40.7 \pm 2.00$ & $10.6 \pm 1.43$ & $29.8 \pm 1.62$ & $20.4 \pm 1.37$ \\
CFC & $26.5 \pm 2.66$ & $14.6 \pm 1.98$ & $29.9 \pm 2.18$ & $38.1 \pm 1.88$ \\
BFC & $32.4 \pm 1.08$ & $10.5 \pm 1.02$ & $27.6 \pm 1.39$ & $47.0 \pm 1.72$ \\
MFC & $43.3 \pm 2.39$ & $14.6 \pm 1.74$ & $53.2 \pm 1.42$ & $44.6 \pm 1.43$ \\
AFC & $41.2 \pm 1.54$ & $13.8 \pm 1.42$ & $65.6 \pm 3.44$ & $52.4 \pm 1.54$ \\
\hline
\end{tabular}

Mean \pm SE $(n=3)$.
Table 5 Cytotoxic screening of various fractions of $\boldsymbol{C}$. opaca fruit against brine shrimps after 24 hours

\begin{tabular}{lllll}
\hline Extracts & $\mathbf{1 0} \mathbf{~ p m}$ & $\mathbf{1 0 0} \mathbf{p p m}$ & $\mathbf{1 0 0 0} \mathbf{p p m}$ & LD $_{\mathbf{5 0}}(\mathbf{p p m})$ \\
\hline HFC & $29.37 \pm 1.23$ & $45.28 \pm 1.33$ & $60.38 \pm 1.43$ & 420 \\
EFC & $34.62 \pm 1.11$ & $50.45 \pm 1.01$ & $62.44 \pm 1.89$ & 100 \\
CFC & $48.21 \pm 2.11$ & $80.42 \pm 2.41$ & $88.44 \pm 2.11$ & 20 \\
BFC & $29.34 \pm 3.42$ & $57.3 \pm 2.98$ & $72.21 \pm 2.33$ & 80 \\
MFC & $32.13 \pm 2.45$ & $71.45 \pm 3.42$ & $89.43 \pm 1.23$ & 55 \\
AFC & $40.11 \pm 2.99$ & $56.34 \pm 2.19$ & $67.42 \pm 2.66$ & 60 \\
\hline
\end{tabular}

Mean \pm SE $(n=3)$.

\section{Antitumor screening}

Potato disc assay was performed to reveal the antitumor potential of various fractions of $C$. opaca fruit. This assay has been routinely used due to its rapid, economical and statistically valid prescreening for antitumor activity. In the present study, Agrobacterium tumefaciens (AT 10) was used against three different concentrations (10, 100 and $1000 \mathrm{ppm}$ ) of different fractions of $C$. opaca fruit. Tumor inhibition was calculated through $\mathrm{IC}_{50}$ value. The $\mathrm{IC}_{50}$ values of antitumor potential of plant samples are summarized in Table 6. Data obtained indicated that the order of $\mathrm{IC}_{50}$ of various fractions of $C$. opaca fruits for antitumor screening was BFC $>$ AFC $>$ CFC $>$ MFC $>$ EFC and HFC.

\section{Discussion}

Phytochemicals screening is carried out to allow isolation of novel or valuable components with potential activities at the earliest stages thus economically very important. Present study exposed the naturally occurring dietary substances such as alkaloids, flavonoids, saponins, tannins and other bioactive metabolites in various fractions of plant samples. Methanol fraction of C.apaca showed the presence of important flavonoid i.e., orientin, isoquercetin, myricetin and apigenin. possess anti-disease wealth particularly minimizes the risk of cancer [20]. In literature, many medicinal plants indicated their strength through antimicrobial and anticancer behavior that was endorsed with high concentration of flavonoids and alkaloids [21,22]. Flavonoids, a large group of phenolics also described as

Table 6 Antitumor screening of various fractions of C. opaca fruit against potato disc tumor after 21 days

\begin{tabular}{lllll}
\hline Extracts & $\mathbf{1 0} \mathbf{~ p p m}$ & $\mathbf{1 0 0} \mathbf{p p m}$ & $\mathbf{1 0 0 0} \mathbf{p p m}$ & $\mathbf{I C}_{\mathbf{5 0}} \mathbf{( p p m )}$ \\
\hline HFC & $12.76 \pm 1.78$ & $23.22 \pm 1.00$ & $30.98 \pm 1.33$ & $>1000$ \\
EFC & $19.11 \pm 1.62$ & $27.44 \pm 1.02$ & $39.56 \pm 1.98$ & $>1000$ \\
CFC & $25.76 \pm 2.19$ & $69.35 \pm 2.36$ & $83.55 \pm 3.15$ & 60 \\
BFC & $40.56 \pm 1.82$ & $65.17 \pm 2.33$ & $72.44 \pm 2.32$ & 40 \\
MFC & $32.61 \pm 1.26$ & $60.45 \pm 1.28$ & $80.33 \pm 2.99$ & 65 \\
AFC & $28.27 \pm 2.41$ & $70.54 \pm 2.52$ & $76.00 \pm 2.54$ & 55 \\
Positive control & $49.2 \pm 1.2$ & $69.5 \pm 2.3$ & $88.9 \pm 3.2$ & 11 \\
\hline
\end{tabular}

Mean \pm SE $(n=3)$. 
nature loving drugs, owned various biological actions [23] like anti-inflammatory aptitude flavonoid containing Chinese medicine $[24,25]$. Thereby, presence of flavonoids in C. opaca can verify their folkloric use against cancer, skin infections and rheumatism. This study is a preliminary estimation of antimicrobial activity of C. opaca fruits. The results of the antibacterial and antifungal activity vary with the fractions of the plant studied. It could result in the discovery of new chemical classes that may possibly proceeded as biochemical tools to study infectious diseases and endowed with selective agents for antibiotics. Our results suggest that antimicrobial activity of plant fractions doesn't depends on only phenolics but other secondary metabolites are also involved. Previous studies revealed that plant extracts have bactericidal effects and consequently seems to be promising in for treatment of microorganisms [26]. Another interesting point is that none of the fractions showed activity against the Gram positive bacteria, Micrococcus luteus and the Gram negative bacteria, Escherichia coli and consequently for rest of the strains they were active. Flavonoids are known to possess antibacterial activity and, according to Tsuchiya et al. [27], dihydroxylation of the A and B rings and substitution with a specific aliphatic group are important for the antimicrobial activity of certain flavanones. Our results of antibacterial activity are in accord to the results of Kil et al. [28] and Martini and Eloff [29] who reported antimicrobial activity of different fractions of Sorghum and Cicer erythrophyllum, respectively. As previous reports suggest that Gram negative bacteria are additionally resistant as compare to Gram positive bacteria, the non polar fractions were the only ones to show activity against Gram-negative bacteria [30]. But in our findings other polar fractions also showed higher activity against Gram-negative bacteria representing combined effects of different phytochemicals found in each fraction. It may be possible that polarity of the polar chemicals like tannins, flavonoids and alkaloids present in fractions can interact with the chemical composition of the polar cell structure of this type of bacteria. Flavonoids as well as triterpenoids and alkaloids could be responsible for the antimicrobial activities [31]. For the investigation of anticancer bioactive compounds, biological assays especially brine shrimp lethality assay (BSLA) is considered as necessary and suitable tools. The variation in BSLA results showed the presence and synergistic effects of a variety of bioactive compounds. Our observations were in accordance with Peteros and Uy [23] who reported that the quantity and quality of secondary metabolites like flavonoids, tannins etc. determine the potential of cytotoxicity of extracts, possibly responsible for difference in results. According to Meyer et al. [18] who categorized crude extracts and pure compounds into toxic $\left(\mathrm{LC}_{50}\right.$ value $\left.<1000 \mathrm{ppm}\right)$ and nontoxic $\left(\mathrm{LC}_{50}\right.$ value $\left.>1000 \mathrm{ppm}\right)$, all tested showed good brine shrimp larvicidal activity. Moreover, Peteros and Uy [23] signified the presence of effective cytotoxic substances of plant extracts having $\mathrm{LC}_{50}$ values $<100 \mathrm{ppm}$ to brine shrimp lethality.

\section{Conclusion}

Most of the tested fraction showed substantial antimicrobial, antitumor and anticancer activities, which is in accordance with the spacious use of tested plant samples in primary health care. It can be concluded that, studied plant parts are accessible source of ethno pharmacy as they are consumed in different areas of Pakistan with ultimate health compensations.

\section{Competing interests}

The authors declare that they have no competing interests.

\section{Authors' contributions}

SS made significant contribution to acquisition of data, analysis, drafting of the manuscript. MRK has made substantial contribution to conception and design, interpretation of data, drafting and revising the manuscript for intellectual content. RAK (ORCID ID: 0000-0003-0453-2090) participated in the design and collection of data and analysis. All authors read and approved the final manuscript.

\section{Acknowledgements}

We are thankful to Higher Education Commission, Islamabad, Pakistan for provision of research funds for the completion of these findings.

\section{Author details}

${ }^{1}$ Botanical Sciences Division, Pakistan Museum of Natural History, Garden Avenue, Shakarparian, Islamabad, Pakistan. Department of Biochemistry, Faculty of Biological Sciences, Quaid-i-Azam University Islamabad, Islamabad, Pakistan. ${ }^{3}$ Department of Biotechnology, Faculty of Biological Sciences, University of Science and Technology, 28100 Bannu, KPK, Pakistan.

Received: 15 February 2013 Accepted: 18 December 2013

Published: 27 December 2013

\section{References}

1. Nazimuddin S, Qaiser M: Apocynaceae. In Flora of Pakistan. Edited by Nasir E, Ali SI. Karachi: Department of Botany, University of Karachi; 1983:11-13.

2. Jabeen A, Khan MA, Ahmad M, Zafar M, Ahmad F: Indigenous uses of economically important flora of Margalla Hills National Park, Islamabad Pakistan. Afric J Biotechnol 2009, 8(5):763-784.

3. Saghir IA, Awan AA, Majid S, Khan MA, Qureshi SJ, Bano S: Ethnobotanical studies of Chikar and its allied areas of District Muzaffarabd. Online J Biological Sci 2001, 1:1165-1170.

4. Abbasi AM, Khan MA, Ahmad M, Zafar M, Khan H, Muhammad M, Sultana S: Medicinal plants for the treatment of jaundice and hepatitis based on socio-economic documentation. Afric J Biotechnol 2001, 8(8):1643-1650.

5. Adhikari BS, Babu MM, Saklani PL, Rawat GS: Distribution, use pattern and prospects for conservation of medicinal shrubs in Uttaranchal State. India. J Mountain Sci 2001, 4(2):155-180.

6. Khan RA: In vitro antioxidant activity and assessment of flavonoids contents of Sonchus arvensis. Chem Central J 2012, 7:54.

7. Sahreen S, Khan MR, Khan RA: Evaluation of antioxidant activities of various solvent extracts of Carissa opaca fruits. Food Chem 2010, 122:1205-1211.

8. Khan RA, Khan MR, Sahreen S: Assessment of flavonoids contents and in vitro antioxidant activity of Launaea procumbens. Chem Central J 2012, 6:43.

9. Khan RA, Khan MR, Sahreen S, Ahmed M: Evaluation of phenolic contents and antioxidant activity of various solvent extracts of Sonchus asper (L.) Hill. Chem Central J 2012, 6:12. 
10. Rojas R, Bustamante B, Bauer J, Fernández I, Albán J, Lock O: Antimicrobial activity of selected Peruvian medicinal plants. J Ethnopharmacol 2003, 88:199-204.

11. Sharma HM: Food Chem 2009, 112:885-888. [Online] Available: http:// zolengthe.blog.co.in /2008/06/27/the ethnomedicinal-use-of-croton/ from Teucrium polium L.

12. McLaughlin $J$, Rogers $L L$ : The use of biological assays to evaluate botanicals. Drug Inform J 1998, 32:513-524.

13. Bagamboula CF, Uyttendaele M, Debevere J: Antimicrobial effect of spices and herbs on Shigella sonnei and Shigella flexneri. J Food Prot 2003, 66:668-673.

14. McLaughlin JL: Crown gall tumors on potato discs and brine shrimp lethality: two single bioassays for plant screening and fractionation. In Methods in Plant Biochemistry. Edited by Hostettmann K. London: Academic Press; 1991:1-31.

15. Meyer BN, Ferrrigni NR, Putnam JE, Jacobsem LB, Nichols DE, Mclaughlin JL: Brine shrimp: a convenient general bioassay for active plant constituents. Planta Med 1982, 45:31-34.

16. Galsky AG, Wilsey JP, Powell RG: Crown gall tumor disc bioassay: a possible aid in the detection of compounds with antitumor activity. Plant Physiol 1980, 65:184-185.

17. Duraipandiyan $V$, Ignacimuthu $S$ : Antibacterial and antifungal activity of Flindersine isolated from the traditional medicinal plant, Toddalia asiatica (L.) Lam. J Ethnopharmacol 2009, 123:494-498.

18. Meye-Alber A, Hartmann H, Sumpel F, Creutzfeldt W: Mechanism of insulin resistance in $\mathrm{CCl}_{4}$-induced cirrhosis of rats. Gastroenterol 1992, 102:223-229.

19. Ferrigini NR, Putnam JE, Anderson B, Jacobsen LB, Nichols DE, Moore DS, McLaughlin JL, Powell PG, Smith CR Jr: Modification and evaluation of the potato disc assay and antitumor screening of Euphorbiacae seeds. J Natural Prod 1982, 45:679-686.

20. Etuk EU, Agaie BM, Ladan MJ, Garba I: The modulatory effect of Cochlospermum tinctorium a rich aqueous root extract on liver damage induced by carbon tetrachloride in rats. Afric J Pharm Pharmacol 2009, 3(4):151-157.

21. Miller NJ, Rice-Evans CA: The relative contributions of ascorbic acid and phenolic antioxidants to the total antioxidant activity of orange and apple fruit juices and blackcurrant drink. Food Chem 1997, 60:331-337.

22. Sharififar F, Dehghn-Nudeh G, Mirtajaldini M: Major flavonoids with antioxidant activity from Teucrium polium L. Food Chem 2009, 112:885-888.

23. Peteros NP, Uy MM: Antioxidant and cytotoxic activities and phytochemical screening of four Philippine medicinal plants. J Medicinal Plants Res 2010, 4(5):407-414

24. Jiang H, Zhan WQ, Liu X, Jiang SX: Antioxidant activities of extracts and flavonoid compounds from Oxytropis falcate Bunge. Natural Prod Res 2008, 22(18):1650-1656.

25. Wu JH, Tung YT, Chien SC, Wang SY, Kuo YH, Shyur LF, Chang ST: Effect of phytocompounds from the heart-wood of Acacia confusa on inflammatory mediator production. J Agric Food Chem 2008, 56:1567-1573

26. Zampini IC, Cuello S, Alberto MR, Ordonez RM, Almeida RD, Solorzano E, Isla M: Antimicrobial activity of selected plant species from "the Argentine Puna" against sensitive and multi-resistant bacteria. J Ethnopharmcol 2009, 124:499-505

27. Tsuchiya T, Gouda N, Konishi T: Relaxation processes in one-dimensional self-gravitating many-body systems. Physiol Rev 1996, 53(3):2210-2221.

28. Kil HY, Seong ES, Ghimire BK, Chung I-M, Kwon SS, Goh EJ, Hoe K, Kim MJ, Lim JD, Lee D, Yu CY: Antioxidant and antimicrobial activities of crude sorghum extract. Food Chem 2009, 115:1234-1239.
29. Martini N, Eloff JN: The preliminary isolation of several antibacterial compounds from Combretum erythrophyllum (Combretaceae). J Ethnopharmacol 1998, 62:255-263.

30. Khan RA, Ahmad M, Khan MR, Yasir M, Muhammad B, Khan R: Nutritional investigation and biological activities of Parthenium hysterophorus. Afric $J$ Pharm Pharmacol 2009, 4:2073-2078.

31. Al-Fatimi M, Wurster M, Schroder G, Lindequist U: Antioxidant, antimicrobial and cytotoxic activities of selected medicinal plants from Yemen. J Ethnopharmacol 2007, 111:657-666.

doi:10.1186/1472-6882-13-372

Cite this article as: Sahreen et al:: Estimation of flavoniods, antimicrobial, antitumor and anticancer activity of Carissa opaca fruits. BMC Complementary and Alternative Medicine 2013 13:372

\section{Submit your next manuscript to BioMed Central and take full advantage of:}

- Convenient online submission

- Thorough peer review

- No space constraints or color figure charges

- Immediate publication on acceptance

- Inclusion in PubMed, CAS, Scopus and Google Scholar

- Research which is freely available for redistribution

Submit your manuscript at www.biomedcentral.com/submit
C Biomed Central 